\title{
Ventoluft Polyherbal formulation modulates Freund's Complete Adjuvant induced arthritis in experimental rats
}

\author{
Research Article
}

\section{Nikita A Sadalage1*, Nayeem A Khatib1, Sunil S Jalalpure², Shrinivas Patil ${ }^{3}$, Mrityunjaya B Ullagaddi ${ }^{1}$}

1. Department of Pharmacology and Toxicology, 2. Department of Pharmacognosy and Phytochemistry, KLE College of Pharmacy Belagavi, KLE Academy of Higher Education and Research (KAHER), Belagavi, 3. Shri Ayurveda Clinic Opposite. Ajanta Hotel, RPD Cross, Tilkawadi Belagavi.

\begin{abstract}
Background: Ventoluft Polyherbal formulation composes multiple traditional medicinal plants composed of various anti-inflammatory agents. Hence, the present study aimed to investigate the effect of Ventoluft Polyherbal formulation on Freund's complete adjuvant-induced arthritic male Wistar rats. Materials and methods: The study included thirty-six rats, containing six in each. Arthritis was induced by injecting FCA $(0.1 \mathrm{ml})$ in joints of the right sub-plantar region of rats in negative control and all test groups i.e. (20,40, and $80 \mathrm{mg} / \mathrm{kg} \mathrm{p.o}$ ) for 28 days except normal group. A positive control, indomethacin $(10 \mathrm{mg} / \mathrm{kg}$, i.p.) was also tested for 28 days. During the treatment, paw volume was measured weekly once. At the end of the experiment, physical, hematological, and biochemical effects were evaluated. Results:Administration of Ventoluft at the doses of 20,40 , and $80 \mathrm{mg} / \mathrm{kg}$ b.w. p.o exhibited statistically significant $(\mathrm{p}<0.001)$ inhibition of the paw edema and joint swelling, along with an increase in body weight, decrease in rheumatoid and spleen index factors. Conclusion: The results from hematological and biochemical parameters have shown that Ventoluft possesses potent anti-arthritic activity, Results obtained in the present study indicate that Ventoluft formulation has exhibited, dose-dependent improvement in FCA induced rheumatoid arthritis.
\end{abstract}

Key Words: Anti-arthritic activity, Freund's Complete Adjuvant, Rheumatoid arthritis, Paw edema, Ventoluft.

\section{Introduction}

Arthritis is a chronic autoimmune disorder that causes synovial inflammation by severely affecting synovial joints and destroys the bone. Arthritis primarily attacks the joints rather than muscles and organs which leads to the destruction of cartilage (1). RA affects roughly 0.5 percent to 1.0 percent of people worldwide, and women are more likely than men to be affected. RA has also been associated with a high death rate (2). Immunization adjuvants essentially increase the immunological response. On the other hand, the right selection of adjuvants based on their attributes and side effects is crucial. Among the numerous classifications of adjuvants, Complete Freund's adjuvant is the most preferred adjuvant for testing the immunogenicity of mouse antigen (3). Because it closely resembles human physiological nature, Freund's complete adjuvant model is one of the most commonly rheumatoid arthritis

\section{* Corresponding Author:}

\section{Nikita A Sadalage}

Department of Pharmacology and Toxicology,

KLE College of Pharmacy Belagavi, KLE Academy

of Higher Education and Research (KAHER),

Belagavi-590010. India

Email Id: nikita14122@gmail.com animal models which causes synovial hyperplasia, leukocyte infiltration, and cartilage deterioration $(4,5)$.

The most frequent treatments for rheumatoid arthritis include non-steroidal anti-inflammatory drugs (NSAIDs), corticosteroids, and disease-modifying antirheumatic drugs (DMARDs), as well as biological. However, these drugs' effectiveness is impeded by significant side effects, encouraging arthritis patients to look for alternatives (6). Indian traditional medicine and Chinese medicine are chosen for arthritis treatment (7-8). Ayurveda literature, on the other hand, has represented polyherbal (9). Blended extracts of individual plants have more activity than individual extracts, according to studies (10).

Ventoluft is a polyherbal formulation that includes sixteen herbal compounds (Pluchea lanceolata, Boerhaavia diffusa, Tribulus terrestris, Tinospora cordiofolia, Balsamodendron mukul, Ricinus communis, Withania somnifera, Pueraria tuberosa, Salmalia malabarica, Phyllanthus emblica, Terminalia chebula, Terminalia belerica, Zingiber officinale, $\mathrm{n}$ Piper nigrum, Piper longum and Acorus calamus produced by Progen Research Lab in Belagavi for the treatment of arthritic patients. Its safety and effectiveness have not been scientifically tested using pre-clinical study. Hence, the present study aimed to investigate the effect of Ventoluft formulation in FCAinduced arthritis by evaluating paw edema, joint 
diameter, haematological parameters, spleen index, and hepatic enzymes.

\section{Materials and methods}

\section{Animals and experimental design}

Male Wistar rats were procured through In-vivo Bioscience, Bangalore. The animals were housed at cages with stainless steel furnished with paddy husk, at suitable temperature and humidity. The rats were feed with food and water over 7 days. The experimental protocol was previous authorized by the Institutional Animal Ethics Committee, KLE College of Pharmacy, Belagavi. ResolutionNo.KLECOP/ CPCSEAReg.No.221/Po/Re/S/2000/ CPSEA,Re.28-12/10/2019. All the experiments were conducted with firm guidelines as per "Committee for the Purpose of Control and Supervision of Experiments on Animals".

\section{Study design and grouping of animals.}

The animals were divided into 6 groups of six animals each as follows:

- Group I: Normal (Received normal saline)

- Group II: FCA group (Injected with $0.1 \mathrm{ml}$ with FCA into the sub-plantar region of right hind paw)

- Group III: Drug-treated animals: received Ventoluft $(20 \mathrm{mg} / \mathrm{kg}$, p.o).

- Group IV: Drugs treated animals: received Ventoluft $(40 \mathrm{mg} / \mathrm{kg}$, p.o).

- Group V: Drug-treated animals: received Ventoluft $(80 \mathrm{mg} / \mathrm{kg}$, p.o).

- Group VI: Standard treated animals: received Indomethacin $(10 \mathrm{mg} / \mathrm{kg}$, i.p).

Each rat was injected with $0.1 \mathrm{ml}$ of Freund's complete adjuvant (FCA) into the sub-plantar region of the right hind paw. Anti-arthritic Ventoluft was evaluated on physical parameters such as joint diameter, bodyweight, and paw edema, once a week. On the 29th day, the blood was withdrawn from retro-orbital puncture for assessing hematological (WBC, RBC, $\mathrm{Hb}$, andESR) and biochemical (AST, ALT, RF, and CRP) parameters, later there were studied for joint histology.

\section{Physical Parameters}

Paw volume and joint diameter were performed using Plethysmometer and Vernier Calipers respectively. Further, Spleen Index was calculated using the following formula:

\section{Estimation of biochemical and hematological parameters}

At the end of the study, Rheumatoid Factor level, CRP, SGOT, and SGPT were evaluated. Further, Hematological parameters like RBC, WBC, Hb level, and ESR were also quantified.

\section{Histopathological studies of joints.}

At the end of the study, ankle joints were removed from the hind paw of the animals and were isolated and kept in 10\% formalin. The organs were later stained with hematoxylin-eosin [11]. Later, the sections were examined using a light microscope.

\section{Statistical analysis}

The results were expressed as mean \pm SEM. Statistical comparison was made between drugs treated groups and arthritic-control groups. Result data such as (Hematological, Biochemical parameters, and spleen index) was calculated using one-way ANOVA followed by Turkey's comparison test. Data of repeated measures (Paw edema, Joint Diameter, Bodyweight) were analyzed using two-way ANOVA followed by "Bonferroni Post-Test" for multiple comparisons. Statistical analysis was done using "Graph Pad Prism 5". P-value $\mathrm{P}<0.05$ was considered statistically significant.

\section{Results}

Effect of Ventoluft on paw edema and Joint Diameter On the 0th day, all groups had their paw volume and joint diameter measured. On the seventh day, the FCA-induced group had a significant increase in paw volume and joint diameter $(\mathrm{P}<0.001)$ when compared to the normal. On the third and fourth weeks, the treatment groups, as well as the STD group, demonstrated a reduction in paw edema and joint diameter as compared to the FCA group. When compared to the FCA treated group, treatment groups showed dose-dependent reductions in paw edema and joint swelling. Figures 1 and 2 depict the data.

\section{Fig: 1. Effect of Ventoluft on Paw Edema in FCA} induced arthritic rats.

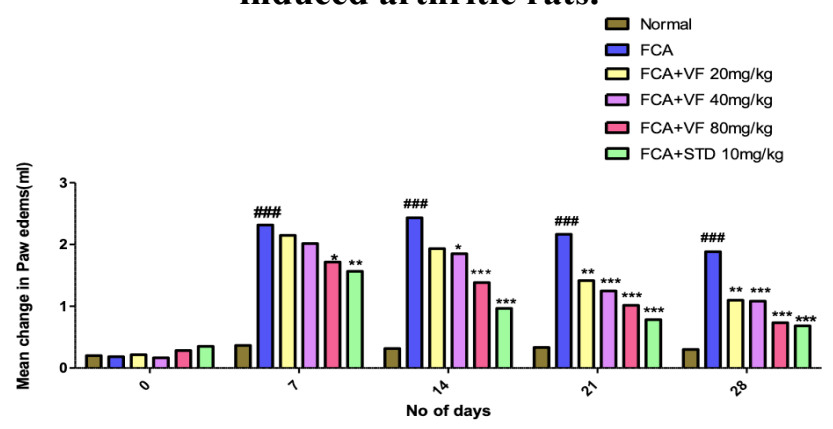

Values are expressed in Mean \pm SEM; $n=6$; Analysed by two-way ANOVA "Bonferroni Post Test" for multiple comparisons tests. \#\# $<<0.001$ when compared to normal, ${ }^{* *} \mathrm{P}<0.001,{ }^{* *} \mathrm{P}<0.01$ and ${ }^{*} \mathrm{P}<0.05$ when compared to FCA, FCA: Freund's Complete Adjuvant; VF: Ventoluft formulation

Fig: 2. Effect of Ventoluft on Joint Diameter in FCA induced arthritic rats.

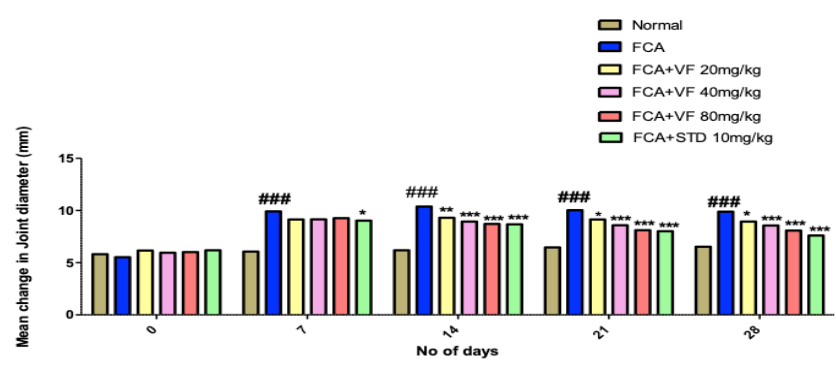


Values are expressed in Mean \pm SEM; $n=6$; Analysed by two-way ANOVA "Bonferroni Post Test" for multiple comparisons. \#\# $\mathrm{P}<0.001$ when compared to normal, ${ }^{*} \mathrm{P}<0.05,{ }^{* *} \mathrm{P}<0.01$ and ${ }^{* * *} \mathrm{P}<0.001$ when compared to FCA.FCA: Freund's Complete Adjuvant; VF: Ventoluft formulation.

\section{Effect of Ventoluft on Body Weight in rats}

From the 7th day until the end of the study, the FCA-induced group had a lower body weight $(\mathrm{P}<$ 0.001) than the control group. Since 14 days, the bodyweight of disease control rats has gradually declined. Treatment with Ventoluft $(20,40$, and $80 \mathrm{mg} /$ $\mathrm{kg} \mathrm{p.o)} \mathrm{in} \mathrm{combination} \mathrm{with} \mathrm{the} \mathrm{STD} \mathrm{group} \mathrm{resulted} \mathrm{in} \mathrm{a}$ considerable and dose-dependent weight gain. Figure 3 depicts the data.

\section{Fig: 3. Effect of Ventoluft on Body Weight in FCA} induced arthritic rats.

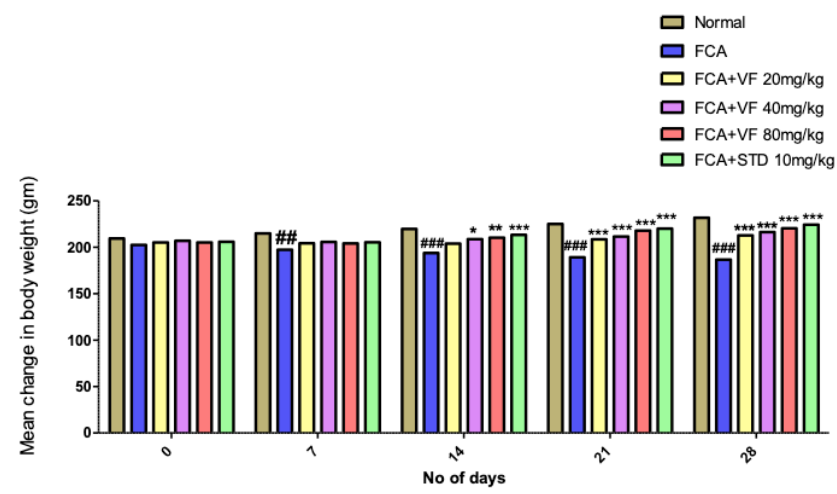

Values are expressed in Mean \pm SEM; $n=6$; Analysed by two-way ANOVA "Bonferroni Post Test" for multiple comparisons. ${ }^{\#} \mathrm{P}<0.01$ and ${ }^{\# \# P} \mathrm{P}<0.001$ when compared to the normal group, ${ }^{*} \mathrm{P}<0.05,{ }^{* *} \mathrm{P}<0.01$ and ${ }^{* * *} \mathrm{P}<0.001$ when compared to FCA, FCA: Freund's Complete Adjuvant; VF:Ventoluft formulation

\section{Effect of Ventoluft on non-injected left Paw Edema}

On the 14th day, the latent secondary swelling that emerges after a few days of joint pain in the Wistar rat's left paw became visible. When compared to the arthritic control group, the treatment of Ventoluft $(20,40$, and $80 \mathrm{mg} / \mathrm{kg}$ p.o) in combination with STD considerably $(\mathrm{P}<0.001)$ diminished joint secondary edema. Figure 4 depicts the data.

Fig: 4. Effect of Ventoluft on non-injected left Paw Edema (secondary response) in FCA induced arthritic rats

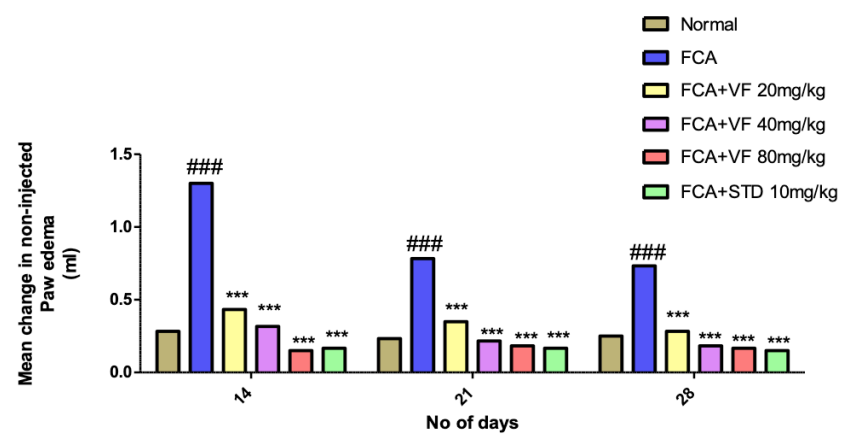

Values are expressed in Mean $\pm \mathrm{SEM}$; $\mathrm{n}=6$; Analyzed by two-way ANOVA "Bonferroni Post Test" for multiple comparisons, ${ }^{\prime \prime} \mathrm{P}<0.001$ when compared to the normal group, ${ }^{* * *} \mathrm{P}<0.001$ when compared to FCA, FCA: Freund's Complete Adjuvant; VF: Ventoluft formulation

\section{Effect of Ventoluft on hematological parameters}

Table 1 shows that the FCA-induced rats had a lower $\mathrm{RBC}, \mathrm{Hb}$ level, and a higher ESR and WBC count compared to normal. All of these indicate that anemia is a prevalent occurrence among chronic arthritic patients (12). In comparison to the arthritic control, the selective dosages of Ventoluft $80 \mathrm{mg} / \mathrm{kg}$ p.o treated group, as well as the STD group, showed a significant $(\mathrm{P}<0.001)$ increase in $\mathrm{RBC}$ and $\mathrm{Hb}$, as well as a significant drop $(\mathrm{P}<0.001)$ in elevated ESR and WBC count levels. When Ventoluft $(20 \mathrm{mg} / \mathrm{kg}$ and $40 \mathrm{mg} /$ $\mathrm{kg} \mathrm{p.o)} \mathrm{was} \mathrm{compared} \mathrm{to} \mathrm{FCA,} \mathrm{no} \mathrm{significant}$ differences were found.

Table 1: Effect of Ventoluft on hematological parameters in FCA-induced arthritic rats.

\begin{tabular}{|c|c|c|c|c|}
\hline Groups & $\begin{array}{l}\text { WBC } \\
(1000 / \\
\left.\mathbf{m m}^{3}\right)\end{array}$ & $\begin{array}{c}\text { RBC } \\
(\text { millions/ } \\
\left.\text { mm }^{3}\right)\end{array}$ & $\underset{(g / d l)}{\mathbf{H b}}$ & $\begin{array}{c}\text { ESR } \\
(\mathbf{m m} / \\
\mathbf{h r})\end{array}$ \\
\hline Normal & $\begin{array}{c}7.373 \pm \\
0.323\end{array}$ & $\begin{array}{l}5.687 \pm \\
0.3657\end{array}$ & $\begin{array}{l}13.81 \pm \\
0.3284\end{array}$ & $\begin{array}{r}4.207 \pm \\
0.02728\end{array}$ \\
\hline FCA & $\begin{array}{c}11.16 \pm \\
0.4313 \# \# \#\end{array}$ & $\begin{array}{c}3.167 \pm \\
0.04333 \# \# \\
\#\end{array}$ & $\begin{array}{c}8.203 \pm \\
0.3353 \# \text { \# }\end{array}$ & $\begin{array}{c}7.267 \pm \\
0.1875 \# \\
\# \#\end{array}$ \\
\hline $\begin{array}{l}\text { FCA+VF } \\
20 \mathrm{mg} / \mathbf{k g}\end{array}$ & $\begin{array}{l}11.11 \pm \\
0.3564\end{array}$ & $\begin{array}{l}3.433 \pm \\
0.2639\end{array}$ & & $\begin{array}{c}7.37 \pm \\
0.09609\end{array}$ \\
\hline $\mathbf{F C A}+\mathbf{V F}$ & $9.84 \pm$ & $3.833 \pm$ & $10.07 \pm$ & $6.767 \pm$ \\
\hline $40 \mathrm{mg} / \mathrm{kg}$ & 0.68 & 0.2564 & & 0.2488 \\
\hline $\begin{array}{l}\text { FCA+VF } \\
80 \mathrm{mg} / \mathbf{k g}\end{array}$ & $\begin{array}{c}8.06 \pm \\
0.4609^{* *}\end{array}$ & $\begin{array}{c}4.577 \pm \\
0.2307^{*}\end{array}$ & $\begin{array}{c}12.24 \pm \\
0.1715^{* * *}\end{array}$ & $\begin{array}{c}6.047 \pm \\
0.4258^{*}\end{array}$ \\
\hline $\begin{array}{c}\text { FCA+STD } \\
10 \mathrm{mg} / \mathbf{k g}\end{array}$ & $\begin{array}{c}8.1 \pm \\
0.05033^{* *}\end{array}$ & $\begin{array}{l}4.627 \pm \\
0.309^{*}\end{array}$ & $\begin{array}{c}12.38 \pm \\
0.4898^{* * *}\end{array}$ & $\begin{array}{c}5.71 \pm \\
0.2548^{*} \\
*\end{array}$ \\
\hline
\end{tabular}

Values are expressed in Mean \pm SEM; $n=6$; Analysed by one-way ANOVA "Turkey's multiple comparison test", $\# \#$ $\mathrm{P}<0.001$ when compared to the normal group, ${ }^{*} \mathrm{P}<0.05,{ }^{* *} \mathrm{P}<0.01$ and ${ }^{* * *} \mathrm{P}<0.001$ compared to FCA, FCA: Freund's Complete Adjuvant;VF: Ventoluft formulation

\section{Effect of Ventoluft on biochemical parameters}

When compared to control rats, all arthritic rats had elevated levels of AST and ALT. In comparison to the STD group, the Ventoluft treated animals (at dosages of 40 and $80 \mathrm{mg} / \mathrm{kg}$ ) demonstrated a significant (P $<0.001)$ reduction in elevated liver enzymes. When arthritic animals were given Freund's adjuvant, there was a statistically significant $(\mathrm{P}<0.001)$ rise in $\mathrm{RF}$ and CRP levels in the FCA-induced group compared to the control group. The Ventoluft formulation had a similar effect to the STD medication group. When compared to FCA, there were no significant differences in CRP values in the treatment groups. When compared to the FCA-induced group, the Ventoluft and STD group demonstrated a statistically significant $(\mathrm{P}<0.001)$ dropin RF. On all of the biochemical markers, no significant 
changes were seen in the lower treatment group, which is Ventoluft $(20 \mathrm{mg} / \mathrm{kg})$; Table 2.

Table 2: Effect of Ventoluft on Biochemical parameters in FCA induced arthritic rats

\begin{tabular}{|c|c|c|c|c|}
\hline Groups & $\begin{array}{c}\text { AST } \\
\text { (U/L) }\end{array}$ & $\begin{array}{c}\text { ALT } \\
(\mathbf{U} / \mathbf{L})\end{array}$ & $\begin{array}{c}\text { CRP } \\
(\mathbf{m g} / \mathbf{d l})\end{array}$ & $\begin{array}{c}\text { RF } \\
\text { (IU/L) }\end{array}$ \\
\hline Normal & $112.9 \pm$ & $54.29 \pm$ & $1.48 \pm$ & $5.328 \pm$ \\
& 5.474 & 4.229 & 0.2337 & 0.2981 \\
\hline $\mathbf{F C A}$ & $159.6 \pm$ & $85.76 \pm$ & $3.672 \pm$ & $11.33 \pm$ \\
& $3.71 \# \#$ & $5.454 \# \#$ & $0.1574 \# \#$ & $0.4347 \# \#$ \\
$\#$ & $\#$
\end{tabular}

Values are expressed in Mean \pm SEM; $n=6$; Analysed by one-way ANOVA “Turkey's multiple comparison test", \#\#\# $\mathrm{P}<0.001$ when compared to the normal group, ${ }^{*} \mathrm{P}<0.05,{ }^{* *} \mathrm{P}<0.01$ and ${ }^{* * *} \mathrm{P}<0.001$ when compared to FCA, FCA: Freund's Complete Adjuvant; VF: Ventoluft formulation

\section{Effect of Ventoluft on Spleen Index}

When compared to the control group, the FCA group had a significant increase $(\mathrm{P}<0.001)$ in the spleen index. When compared to FCA, the Ventoluft $(80 \mathrm{mg} / \mathrm{kg})$ and STD groups showed a significant drop in the spleen index. (Ventoluft 20 and $40 \mathrm{mg} / \mathrm{kg}$ ) showed no significant differences. Figure 5 depicts the data.

Fig 5: Effect of Ventoluft on Spleen index in FCA induced arthritic rats.

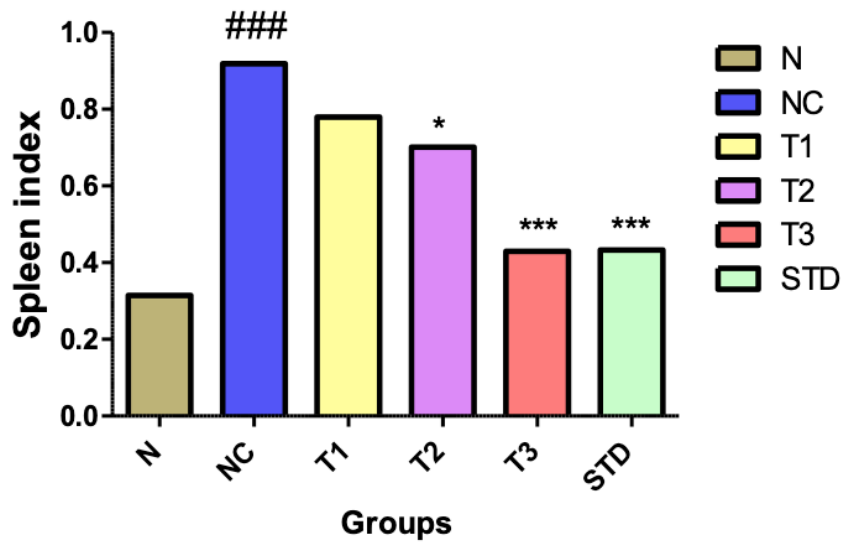

Values are expressed in Mean \pm SEM; $n=6$; Analysed by one-way ANOVA "Turkey's multiple comparison test", \#\#\# $\mathrm{P}<0.001$ when compared to the normal group, ${ }^{*} \mathrm{P}<0.05$ and ${ }^{* * *} \mathrm{P}<0.001$ when compared to FCA.FCA: Freund's Complete Adjuvant; VF: Ventoluft formulation
Effect of Ventolufton histopathological changes of ankle joint tissues

The right hind ankle joints were extracted for histological examination on the 29th day after initial treatment. The rats in the control group exhibited no signs of injury (Fig. 6A). FCA rats' right ankle joints showed significant structural alterations, including pannus development, synovial hyperplasia, bone erosion, and cartilage degeneration. (See Fig. 6B.) Oral treatment of Ventoluft $(20,40,80 \mathrm{mg} / \mathrm{kg}$ ) reduced histopathological alterations and joint histological damage scores as compared to the FCA group (Figs. $6 \mathrm{C}, 6 \mathrm{D}$, and 6E). Ventoluft-treated rats had considerably Lowerjoint and histological damage scores, as demonstrated in (Fig.6E). These findings suggested that the Ventoluft formulation has an anti-arthritis impact; Figure 6.

Figure 6: Histopathology of joints
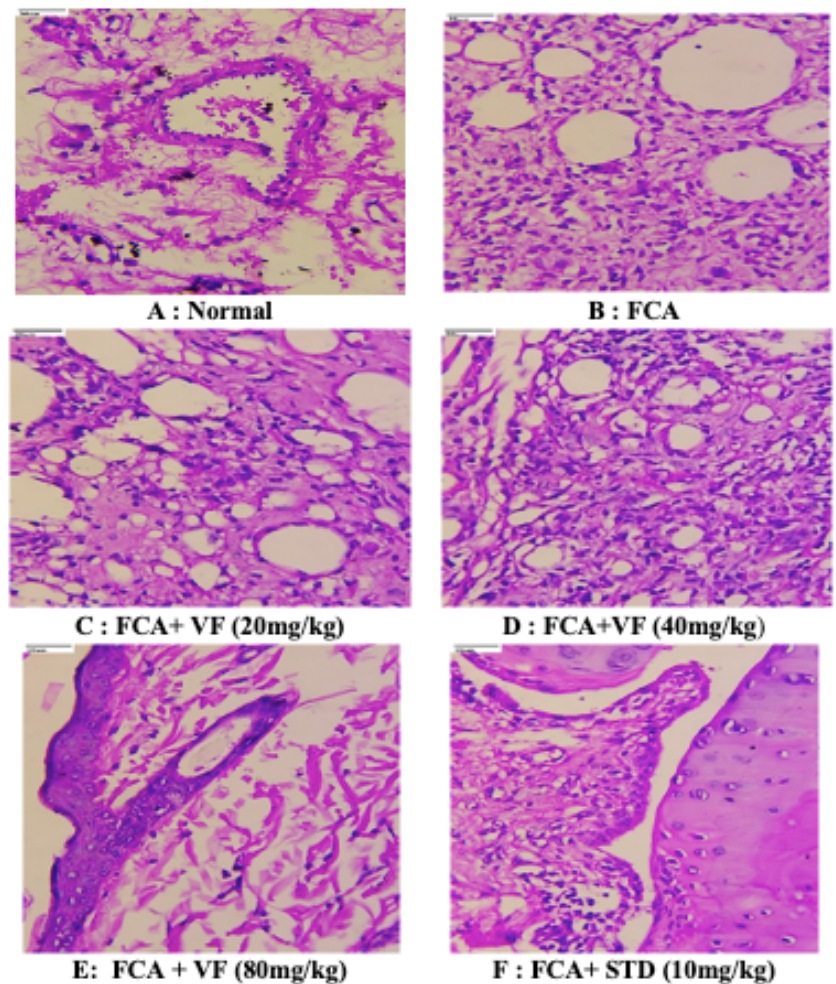

\section{Discussion}

The purpose of this study was to see how the Ventoluft formulation affected FCA-induced arthritis in male Wistar rats. FCA-induced arthritis is associated with increased paw edema and joint diameter, according to the data provided in this study. FCA-induced arthritis causes paw edema and increases joint width in rats, which is consistent with previous studies (13-15). Secondary swelling on the Wistar rat's non-injected left paw which was observed on the $14^{\text {th }}$ day was decreased in Ventoluft treated rats. These observations suggest that Ventoluft has a synergistic effect in reducing paw volume due to secondary reaction. Decreased cellularity of synovial tissue is the major cause of decreased paw edema and joint diameter in Ventoluft treated rats (16). Furthermore, multiple experimental studies on rats, as well as our research, show that the arthritic group had a 
lower body weight. It has previously been established that decreased body weight during inflammation is caused by inadequate nutrient absorption through the colon. Chronic Ventoluft therapy of arthritic mice promoted body weight loss (13). Hepatic involvement is shown in arthritic patients with increased aminotransferases like AST and ALT, indicating the presence of inflammation, as shown in the present rat studies (17). The current study findings show that arthritic groups had greater levels of AST and ALT. However, in rats, the Ventoluft treated groups, as well as the STD group, showed a significant drop in AST and ALT levels, indicating that the illness status had improved. Rheumatoid factors (RF) possess a key role in the etiology of rheumatoid arthritis, according to several clinical investigations (18).

Researchers believe that RF is important for the severity of RA in people who have been exposed to FCA (19). According to current research, FCA-induced groups have a lower RBC count, a lower Hb level, and a higher ESR. Furthermore, these characteristics point to anemia, which is common in RA patients (20). When administered with the Ventoluft formulation, anemia and arthritis symptoms improved, indicating that the test medication has anti-arthritic properties. In clinical investigations, the erythrocyte sedimentation rate (ESR) is a critical diagnostic tool for detecting the progression of inflammation (21). ESR levels are higher in FCAinduced mice. Reduced levels in the Ventoluft treated and STD groups, on the other hand, suggest antiinflammatory capabilities. Several additional important indicators indicate the severity of inflammation. CRP is one of them, and it contributes to the diagnosis of rheumatoid arthritis disease. CRP levels are increased in RA patients, which is consistent with current rat research. Increased CRP levels cause bone injury, according to clinical data (22). CRP levels were recovered in the Ventoluft-treated groups. Arthritis patients, on the other hand, might develop a variety of problems, including Felty's syndrome, which causes an enlarged spleen. Furthermore, we have had to estimate the spleen index in the current investigations. The spleen index was found to be lower in the treated groups, indicating that it is effective in reversing splenomegaly (23).

Necrosis was not present in normal rats, and there was no evidence of lymphocytic infiltration. However, FCA-induced rat necrosis was validated by a massive inflow of inflammatory cells, synovial hyperplasia, and greater levels of necrosis. The regular connective tissue of the tibiotarsal joint was present in the treatment groups, combined with decreased levels of edema.

Even though the Ventoluft formulation has the potential to have a greater effect than individual plant extracts, it has a positive and constructive way, including a lack of knowledge about which chemical constituents are responsible for the rheumatic activity. However, the findings of this study show that the Ventoluft formulation improves FCA-induced rheumatoid arthritis in a dose-dependent manner.
It has been demonstrated that traditional medicinal plants act by targeting multiple proteins and regulating various pathways concerned with infectious and non-infectious pathogenesis (24-28) based on the principle of the regulation of multiple proteins by a single compound $(29,30)$. Hence, it would be required to identify the interaction of the multiple bioactives with their respective targets of the Ventoluft formulation to propose the mechanism of action for anti-arthritic activity.

\section{Conclusion}

Remarkably, Ventoluft like Indomethacin significantly slowed the progression of arthritic illness in our current investigation. The capacity of Ventoluft to considerably diminish arthritic edema in injured tissues is determined by its therapeutic activity. Even though Ventoluft is effective in arthritis patients, the relevance of the model utilized in this study reflects pathological changes in humans, indicating that Ventoluft might be classified as a novel therapeutic agent in the treatment of arthritis.

\section{Acknowledgment}

Freund's adjuvant and Indomethacin were provided by Dr. Prabhakar Kore Basic Science Research Centre, which the authors gratefully acknowledge. Ventoluft formulation was provided by Progen Research Lab in Belagavi, which the authors are grateful for. Thank you to the Principal of KLE College of Pharmacy, KAHER, for providing the necessary infrastructure.

\section{Conflict of interest}

The authors declare no conflict of interest

Financial support Nil

\section{References}

1. Chimagave SS, Jalalpure SS, Kurangi BK. Preparation and development of polyherbal formulation of medicinal plants for antiarthritic activity. Indian Journal of Health Sciences and Biomedical Research (KLEU). 2020 May 1;13(2):120.

2. Kim W, Park S, Choi C, Kim YR, Park I, Seo C, Youn D, Shin W, Lee Y, Choi D, Kim M. Evaluation of antiinflammatory potential of the new ganghwaljetongyeum on adjuvant-induced inflammatory arthritis in rats. Evidence-Based Complementary and Alternative Medicine. 2016 Jan $1 ; 2016$.

3. Apostólico JD, Lunardelli VA, Coirada FC, Boscardin SB, Rosa DS. Adjuvants: classification, modus operandi, and licensing. Journal of immunology research. 2016 Jan 1;2016.

4. Mondal P, Das S, Mahato K, Borah S, Junejo JA, Zaman K. Evaluation of anti-arthritic potential of the hydro-alcoholic extract of the stem bark of Plumeria rubra in freund's complete adjuvant-induced arthritis in rats. International Journal of Pharmaceutical Sciences and Research. 2016 Sep 1;7(9):3675. 
5. Mbiantcha M, Almas J, Shabana SU, Nida D, Aisha F Anti-arthritic property of crude extracts of Piptadeniastrum africanum (Mimosaceae) in complete Freund's adjuvant-induced arthritis in rats. BMC complementary and alternative medicine. 2017 Dec;17(1):1-6.

6. Jalalpure SS, Mandavkar YD, Khalure PR, Shinde GS, Shelar PA, Shah AS. Antiarthritic activity of various extracts of Mesua ferrea Linn. seed. Journal of ethnopharmacology. 2011 Dec 8;138(3):700-4.

7. Choudhary M, Kumar V, Malhotra H, Singh S. Medicinal plants with potential anti-arthritic activity. Journal of intercultural ethnopharmacology. 2015 Apr;4(2):147.

8. Pan HD, Xiao Y, Wang WY, Ren RT, Leung EL, Liu L. Traditional Chinese Medicine as a Treatment for Rheumatoid Arthritis: From Empirical Practice to Evidence-Based Therapy. Engineering. 2019 Oct 1;5(5):895-906.

9. Sara BB, Sailaja AK. A Review on Polyherbal Formulations used in the Treatment of Autoimmune Disease like Rheumatoid Arthritis. Research \& Reviews: Journal of Herbal Science. 2019 May 28;8(1):11-6.

10. Petchi RR, Parasuraman S, Vijaya C, Krishna SG, Kumar MK. Antiarthritic activity of a polyherbal formulation against Freund's complete adjuvant induced arthritis in Female Wistar rats. Journal of basic and clinical pharmacy. 2015 Jun;6(3):77.

11. Hasan H, Ismail H, El-Orfali Y, Khawaja G. Therapeutic benefits of Indole-3-Carbinol in adjuvantinduced arthritis and its protective effect against methotrexate induced-hepatic toxicity. BMC complementary and alternative medicine. 2018 Dec;18(1):1-2.

12. Baer AN, Dessypris EN, Krantz SB. The pathogenesis of anemia in rheumatoid arthritis: a clinical and laboratory analysis. InSeminars in arthritis and rheumatism 1990 Feb 1 (Vol. 19, No. 4, pp. 209-223). WB Saunders.

13. Patel SS, Shah PV. Evaluation of anti-inflammatory potential of the multidrug herbomineral formulation in male Wistar rats against rheumatoid arthritis. Journal of ayurveda and integrative medicine. 2013 Apr;4(2):86.

14. Li N, Liu Q, Li RT, Sun Q, Jiang YM, Ye J. Antiarthritic Effect of the Spirocyclopiperazinium Salt Compound LXM-15 in Rats and Its Underlying Mechanism. Inflammation. 2020 Jan 16:1-3.

15. Sharma H, Chauhan P, Singh S. Evaluation of the antiarthritic activity of Cinnamomum cassia bark extract in experimental models. Integrative medicine research. 2018 Dec 1;7(4):366-73.

16. Singh S, Kumar R, Jain H, Gupta YK. Antiinflammatory and antiarthritic activity of UNIM-301 (a polyherbal unani formulation) in Wistar rats. Pharmacognosy Research. 2015 Apr;7(2):188.

17. Roy T, Banerjee I, Ghosh S, Dhali RS, De Pati A, Tripathi SK. Effects of co-treatment with pioglitazone and methotrexate on experimentally induced rheumatoid arthritis in Wistar albino rats. Indian journal of pharmacology. 2017 Mar;49(2):168.

18. Ingegnoli $F$, Castelli R, Gualtierotti R. Rheumatoid factors: clinical applications. Disease markers. 2013 Oct;35.

19. Rocha SD, Baldo DC, Andrade LE. Clinical and pathophysiologic relevance of autoantibodies in rheumatoid arthritis. Advances in Rheumatology. 2019;59.

20. Wilson A, Yu HT, Goodnough LT, Nissenson AR. Prevalence and outcomes of anemia in rheumatoid arthritis: a systematic review of the literature. The American journal of medicine. 2004 Apr 5;116(7):50-7.

21. Tas F, Erturk K. Elevated erythrocyte sedimentation rate is associated with metastatic disease and worse survival in patients with cutaneous malignant melanoma. Molecular and clinical oncology. 2017 Dec 1;7(6):1142-6.

22. Kim KW, Kim BM, Moon HW, Lee SH, Kim HR. Role of C-reactive protein in osteoclastogenesis in rheumatoid arthritis. Arthritis research \&therapy.2015Dec1;17(1):41.

23. Owlia MB, Newman K, Akhtari M. Felty's syndrome, insights and updates. The open rheumatology journal. 2014;8:129.

24. Duyu T, Khanal P, Khatib NA, Patil BM. Mimosa pudica modulates neuroactive ligand receptor interaction in Parkinson's disease. Indian J Pharm Educ. 2020 Jul 1;54(3):732-9.

25. Duyu T, Khatib NA, Khanal P, Patil BM, Hullatti KK. Network pharmacology-based prediction and experimental validation of Mimosa pudica for Alzheimer's disease. J Phytopharmacol. 2020;9(1):46-53.

26. Patil R, Chikhale R, Khanal P, Gurav N, Ayyanar M, Sinha S, Prasad S, Dey YN, Wanjari M, Gurav SS. Computational and network pharmacology analysis of bioflavonoids as possible natural antiviral compounds in COVID-19. Informatics in medicine unlocked. 2021 Jan 1;22:100504.

27. Khanal P, Patil BM. Integration of network and experimental pharmacology to decipher the antidiabetic action of Duranta repens L. Journal of Integrative Medicine. 2021 Jan 1;19(1):66-77.

28. Khanal P, Patil BM. Consolidation of network and experimental pharmacology to divulge the antidiabetic action of Ficus benghalensis L. bark. 3 Biotech. 2021 May;11(5):1-6.

29. Dwivedi PS, Rasal VP, Kotharkar E, Nare S, Khanal P. Gene set enrichment analysis of PPAR- $\gamma$ regulators from Murraya odorata Blanco. Journal of Diabetes \& Metabolic Disorders. 2021 Feb 17:1-7.

30. Khanal P, Dey YN, Patil R, Chikhale R, Wanjari MM, Gurav SS, Patil BM, Srivastava B, Gaidhani SN. Combination of system biology to probe the anti-viral activity of andrographolide and its derivative against COVID-19. RSC Advances, 2021;11(9):5065-5079. 